\title{
Mycosis fungoides: A case report
}

\author{
Jitender Mohan Khunger $\cdot$ Niti Khunger $\cdot$ Kalpana Azad $\cdot$ Sanjay Srivastava
}

Received: 27 August 2008 / Accepted: 9 December 2008

(C) Indian Society of Hematology and Transfusion Medicine 2010

\begin{abstract}
Mycosis fungoides is the commonest cutaneous $\mathrm{T}$ cell lymphoma. Clinically it is characterized by patch, plaque, tumor nodules; erythrodermic and poikoilodermous stages which may overlap. Extracutaneous spread takes place in late stages where any organ may be involved. The majority of reported cases are in adult males. A rare case of mycosis fungoides in a 38 -year-old female is described. She presented in advance stage of disease with nodules all over the body.
\end{abstract}

Keywords Mycosis fungoides $\cdot$ Tumor stage $\cdot$ Skin · Nodule

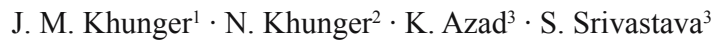

${ }^{1}$ Department of Haematology,

${ }^{2}$ Department of Skin,

${ }^{3}$ Department of Pathology,

V. M. Medical College and

Safdar Jang Hospital, New Delhi, India

J. M. Khunger $(\square)$

E-mail: drjmkhunger@rediffmail.com
}

\section{Introduction}

Mycosis fungoides was first described by Alibert in 1806 as a mushroom like skin neoplastic condition [1]. Its a cutaneous $\mathrm{T}$ cell lymphoma which typically begins as slowly progressive dermatitis like patches and plaques, when untreated evolves to nodules and eventual systemic dissemination [2]. The patch/plaque stage of the disease is the result of intraepidermal and superficial dermal infiltration by small to medium sized malignant $\mathrm{T}$ cells while the more advanced stage develops as a consequence of exclusively dermal involvement of non-epidermotropic malignant $\mathrm{T}$ cells $[2,3]$. The characteristic cell of mycosis fungoides is a small or medium sized lymphocyte with a cerebroid nucleus.

Mycosis fungoides is a disease predominately of adult males, although children are occasionally affected $[2,4]$. It is an indolent type of cutaneous $\mathrm{T}$ cell lymphoma that evolves slowly through skin limited disease to systemic involvement [4]. The disease can become biologically high grade in its later stages.

\section{Case report}

A 38-year-old female was brought to skin department of a tertiary care hospital with history of nodular and papular rashes all over the body, fever and pruritis for the past 6 months. Nodules were $1-3 \mathrm{~cm}$ in size, fleshy tender and mobile over underlying structures but attached to the overlying skin (Fig. 1). She had discrete, mobile, non-tender cervical, axillary and inguinal lymphadenopathy. Splenomegaly and hepatomegaly was also noted.

On laboratory investigations, her hemoglobin was 7.5 $\mathrm{g} \%$, total leucocyte count was $8500 /$ cumm and platelet count was $240,000 /$ cumm. Peripheral smear showed no atypical cells. There was no involvement of the bone marrow. FNAC of the skin lesions revealed features compatible with non-Hodgkin's lymphoma (large cell type). 


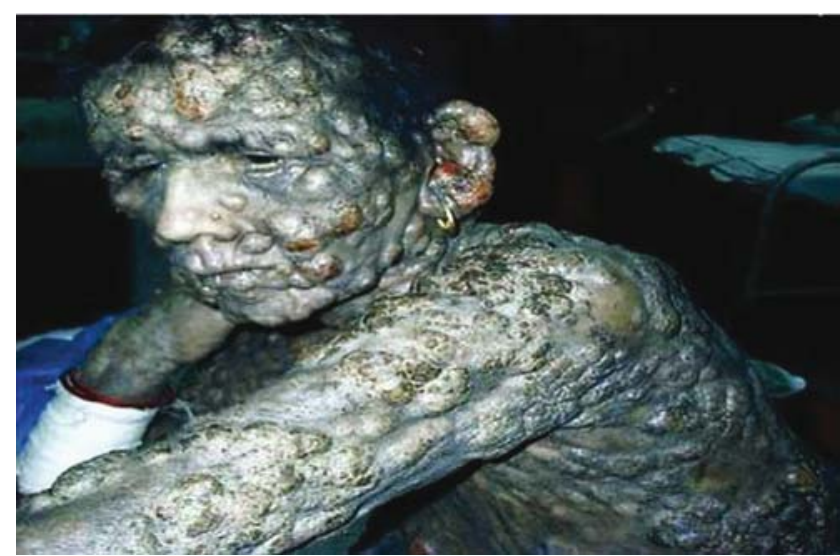

Fig. 1 Photograph of patient with tumor stage of mycosis fungoides

Skin biopsy showed a diffuse lymphoid infiltrate involving the full thickness of epidermis and extending to the subcutaneous dermis, more around the perivascular spaces (Fig. 2). These lymphoid cells were atypical and large with convoluted nuclei. Histopathological diagnosis of mycosis fungoides-tumor stage was made.

Immunohistochemistry showed CD3, CD4 and LCA positivity (Fig. 3).

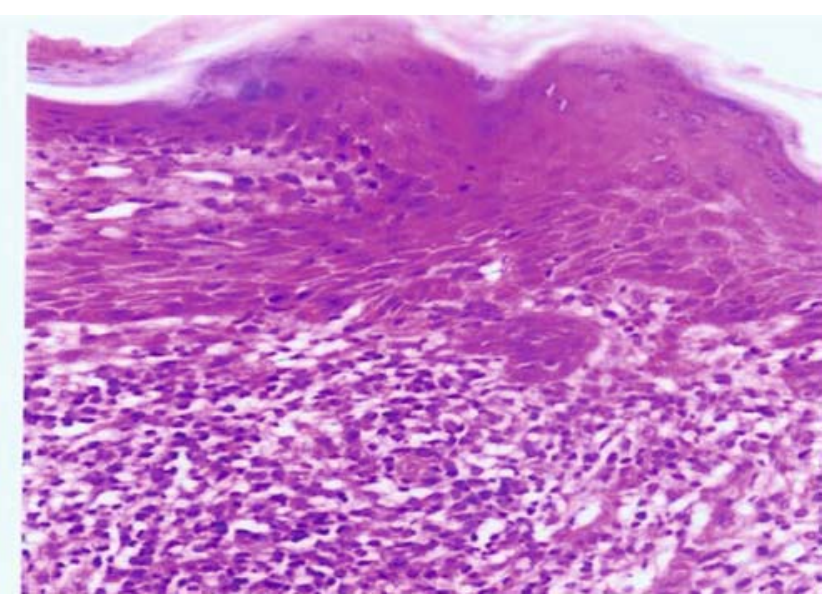

Fig. 2 Photomicrograph of $\mathrm{H}$ and $\mathrm{E}$ stained skin biopsy showing infiltrate by atypical lymphocytes in tumor stage of mycosis fungoides $(10 \times)$

\section{Discussion}

Mycosis fungoides is the $\mathrm{T}$ cell lymphoproliferative disorder that arises primarily in the skin and that may evolve into generalized lymphoma [3, 5]. A viral etiology has been suspected because of certain similarities to HTLV-1 associated adult $\mathrm{T}$ cell leukemia- lymphoma but has not been proved as yet [6]. The majority of the cases occur in adult males but adolescents can also be affected [7]. It has various manners of presentation and progression.

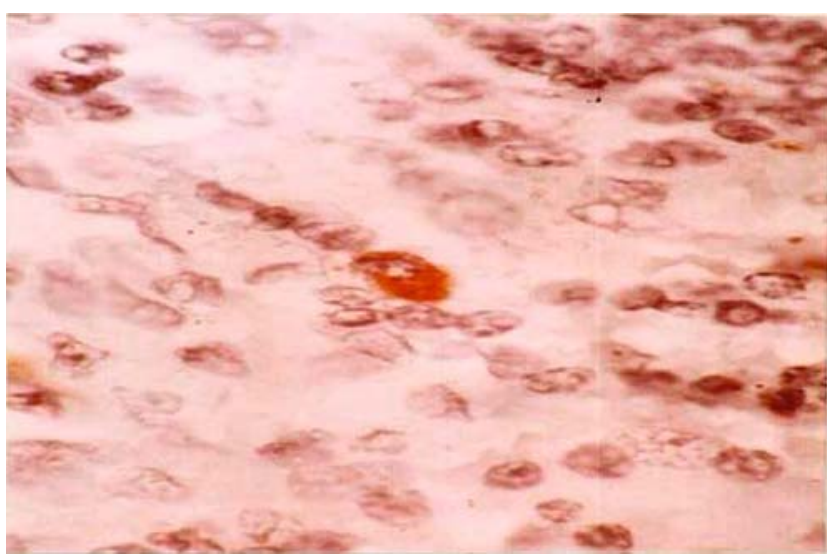

Fig. 3 Immunohistochemistry showing positivity for CD3 in skin biopsy $(40 \times)$

Traditionally, mycosis fungoides is divided into three stages-premycotic, mycotic and tumor stage $[2,7]$. In the premycotic stage, the skin is erythematous, scaly and pruritic. The microscopic appearance may be non-diagnostic represented by chronic nonspecific dermatitis. In the mycotic stage, infiltrative plaques appear and biopsy shows polymorphous inflammatory infiltrate in dermis that contains small number of frankly atypical lymphoid cells. These cells may evade the dermis to form Pautrier's microabscesses. In the tumor stage, dense infiltrates of atypical lymphoid cells expand the dermis. The characteristic cell of mycosis fungoides is a small or medium sized lymphocyte with a cerebroid nucleus. This term cerebroid nucleus refers the highly irregular contour of the thick nuclear membrane, which results in an appearance somewhat reminiscent of brain convolutions [2].

In our case, the patient presented with tumor stage of the disease. She had lymphadenopathy and hepato-splenomegaly indicating an extracutaneous spread. However there were no atypical cells in the peripheral blood, ruling out the possibility of Sezary Syndrome. In mycosis fungoides in cases of extracutaneous spread, lymph node, liver, spleen and lungs are often involved, in addition to the peripheral blood $[2,8]$. Transformation to large highly atypical lymphocytic infiltration in the dermal component is associated with development of an aggressive biological course [4].

Although mycosis fungoides is a malignant lymphoma of low grade malignancy with prolonged survival, important prognostic parameters are stage at diagnosis, absence of complete remission after first treatment [9]. Once extracutaneous spread takes place, prognostic parameters have no influence on survival and prognosis is bad [5]. Sepsis is a frequent terminal complication $[2,9]$.

\section{References}

1. Alibert JLM (1806) Description des Maladies de la peau observes a I Hospital Saint Louis, Paris, Borris 157 
2. Murphy GF, Schwarting R (2005) Cutaneous lymphomas and leukemias. In Lever's histopathology of the skin, 9th edition. Lippincot Williams and Wilkins 927-978

3. Van Doorn R, Van Haselen CW, Voorst Vader PC, et al. (2000) Mycosis fungoides: Disease evolution and prognosis of 309 Dutch patients. Arch Dermatol 136:504-510

4. Vergier B, De Muret A, Beylot-Barry M, et al. (2000) Transformation of mycosis fungoides: Clinicopathological and prognostic features of 45 cases. French study group of cutaneous lymphomas. Blood 95:2212-2218

5. Kim YH, Hoppe RT (1999) Mycosis fungoides and the Sezary syndrome. Semin Oncol 26:276-289
6. Nagatani T, Matsuzaki T, Lemonto G, et al. (1990) Comparative study of cutaneous $\mathrm{T}$ cell lymphoma and adult $\mathrm{T}$ cell lymphoma/leukemia, clinical, histopathologic and immunohistochemical analysis. Cancer 66:2380-2386

7. Barcos M (1993) Mycosis fungoides, diagnosis and pathogenesis. Clin Pathol 99:452-458

8. Glusac EJ (2003) Criterion by criterion, mycosis fungoides. Am J Dermatopathol 25:264-269

9. Zackheim HS, Amin S, Kashani-Saket M, et al. (1999) Prognosis in cutaneous $\mathrm{T}$ cell lymphoma by skin stage: Long term survival in 489 patients. J Am Acad Dermatol $40: 418-425$ 